\title{
A Study of Maternal Mortality in a Tertiary Care Teaching Hospital in Andhra Pradesh, South India
}

\author{
Savitri Somasekhar ${ }^{1}$, Priscilla Bhaskara² \\ 1,2 Department of Obstetrics and Gynaecology, Government General Hospital, Anantapur, Andhra Pradesh, India.
}

\section{ABSTRACT}

\section{BACKGROUND}

Maternal mortality is measure of adequacy of health care system and socioeconomic status of the country. Globally every day thousands of women die of pregnancy related causes, majority in developing countries. It has adverse effect on family, society and country.

\section{METHODS}

In this retrospective study maternal deaths occurring in the Government General Hospital, Anantapur, from Jan 2018 to Oct 2021 were analysed using medical case records

\section{RESULTS}

In present study, a total of 48 maternal deaths, with MMR of 142.35 per one lakh live births were analysed. Maximum number of deaths occurred in age group between 20 to 25 years. $68.75 \%$ were uneducated and $31.25 \%$ had literacy just above 10th class. A majority, $95.8 \%$ belonged to low socioeconomic group. Most cases were unbooked, $91.69 \%$. There were $81.25 \%$ of referred cases and $18.75 \%$ in house cases. G2 G3, primi formed the majority of study population. Major cause of MMR was due to direct cause, $77 \%$. Hypertensive disorders in pregnancy accounted for $35 \%$, obstetric haemorrhage in $25 \%$ followed by pulmonary embolism/AF embolism, $10.4 \%$. Indirect causes accounted for $23 \%$. Anaemia accounted for majority of indirect cause, $72.9 \%$.

\section{CONCLUSIONS}

Majority of maternal deaths occurred in patients from rural areas, unbooked uneducated patients and from poor socioeconomic status. Hypertensive disorders of pregnancy and obstetric haemorrhage are major direct causes of maternal deaths, anaemia being the commonest indirect cause. Access to antenatal care and skilled care during child birth play a vital role in reducing maternal mortality.

\section{KEY WORDS}

Maternal Mortality, Obstetric Haemorrhage, Hypertensive Disorders of Pregnancy, Anaemia.
Corresponding Author: Dr. Savitri Somasekhar, H. No. 46-89/10, Budhawarpeta, Kurnool-518002, Andhra Pradesh, India. E-mail: drsavitrisomasekhar@gmail.com

DOI: $10.14260 /$ jemds/2022/38

How to Cite This Article: Somasekhar S, Bhaskara P. A study of maternal mortality in a tertiary care teaching hospital in Andhra Pradesh, South India. J Evolution Med Dent Sci 2022;11(01):199-202, DOI: 10.14260/jemds/2022/38

Submission 05-12-2021,

Peer Review 13-01-2022,

Acceptance 20-01-2022,

Published 29-01-2022.

Copyright (C) 2022 Savitri Somasekhar et al. This is an open access article distributed under Creative Commons Attribution License [Attribution 4.0 International (CC $B Y 4.0)]$ 


\section{BACKGROUND}

Proper antenatal care and skilled timely care during child birth are key factors in preventing most of maternal deaths. Health care solutions to prevent and manage complications related to maternal mortality are well known. Maternal mortality continues to remain unacceptably high. Globally lakhs of women die of pregnancy related causes, majority from developing countries. Maternal mortality is a measure of adequacy of health care system and socioeconomic status of the country. WHO defines maternal mortality as the death of any pregnant woman or within 42 days of termination of pregnancy, disregarding duration or site of pregnancy, from any cause related to or aggravated by pregnancy but not from accidental or incidental cause.

MMR - maternal death per one lakh live births International definition of maternal mortality ratio.

In 2017, 295000 deaths among women were noted during pregnancy and after childbirth. The vast majority of these deaths (94\%) occurred in low resource settings \& most could have been prevented. Sub-Saharan Africa and Southern Asia together contributed to $86 \%(2,54,000)$ of the estimated global maternal deaths in the year 2017.

Sub-Saharan Africa alone contributed to roughly 2/3 $(1,96,000)$ of maternal deaths while Southern Asia nearly one fifth $(58,000)$ of deaths. Greatest overall reduction in MMR was achieved by Southern Asia between 2000 and 2017 A decline of nearly $60 \%$ - from an MMR of 384 down to 157.1

In 2017, MMR was 462 per one lakh live births in lowincome countries as compared to 11 per one lakh live births in high income countries. ${ }^{1}$ In many parts of the world a large number of maternal deaths indirectly reflect inequalities that exist in accessing to quality health services which in return highlights the gap between rich and poor.

In order to improve the maternal health indicators, the government of India has implemented many initiatives. Much progress has been made in ending preventable maternal deaths in past two decades. MMR of India for the period of 2016-2018 as per latest report of national sample registration system (SRS) data is $113 / 1,00,000$ live births, declining by 17 points from $130 / 1,00,000$ live births in 2014 $2016.2,3$ Focus on quality and coverage of health services through public health initiatives under National Rural Health Mission have contributed to this decline in maternal deaths.

Most of the complications which develop during pregnancy are potentially preventable and treatable. Some complications may antedate pregnancy which deteriorate during antenatal period especially if not managed as part of woman's care. Major complications that account for nearly $75 \% 4$ of all deaths are obstetric haemorrhage, hypertensive disorders of pregnancy - preeclampsia \& eclampsia, sepsis, unsafe abortions \& anaemia. Access to antenatal care, early diagnosis of anaemia \& preeclampsia, safe abortion practices, early interventions to prevent \& treat postpartum haemorrhage, availability of skilled health professional, institutional deliveries - all these may contribute to life and death for the mother. Main factors which deny adequate health care to pregnant women are ignorance, poverty, lack of transport facilities, poor quality services and cultural practices.

\section{METHODS}

This hospital based retrospective study was done in Department of Obstetrics and Gynaecology at Government General Hospital affiliated to GMC (GGH/GMS), Anantapur, Andhra Pradesh. The study was carried out after obtaining approval from Institutional Ethical Committee from January 2018 to October 2021.

\section{Study Tools \& Techniques}

Medical case records of all maternal deaths occurring in the Government General Hospital, Anantapur from Jan 2018 to Oct 2021 were analysed. All cases of maternal mortality were documented in the maternal death review forms with complete information. Various variables- age, residence, parity, antenatal booking, timing of death, time interval between admission and death, referral status and cause of death were collected from medical records department of hospital and maternal death review forms, were analysed.

\section{Exclusion Criteria}

Brought dead cases and deaths due to suicide, homicide and covid related causes were excluded from the study. WHO defines maternal mortality as the death of any pregnant woman or within 42 days of termination of pregnancy, disregarding the duration or site of pregnancy, from any cause related to or aggravated by pregnancy but not from accidental or incidental cause. International formula for MMR is maternal death per 1 lakh live births. ${ }^{2}$

\section{Statistical Analysis}

Data collected was analysed using Microsoft Excel sheet version 2010. Results were analysed by using ratio, percentage and proportion.

\section{RESULTS}

During the study period of 46 months there were 48 maternal deaths giving MMR of 142.35 per one lakh live births = $48 \times 1,00,000 / 33,719.81 .25 \%$ of cases were referred from (CHCS, PHC \& private hospitals) towns and villages around Anantapur. $18.75 \%$ of cases were internal cases of our hospital. Tabulation of results done based on age, mode of delivery, parity index, gestation, socio economic condition, education status and cause of death.

\begin{tabular}{|cccc|}
\hline Year & Total No. of Live Births & Maternal Deaths & MMR \\
2018 & 9181 & 7 & $76.24 \%$ \\
2019 & 9272 & 13 & $140.2 \%$ \\
2020 & 7843 & 13 & $165.75 \%$ \\
2021 (Jan -Oct) & 7423 & 15 & $202.07 \%$ \\
\hline \multicolumn{3}{|c|}{ Table 1. Year Wise Distribution of MMR } \\
\hline \multicolumn{2}{|c|}{ In the present study, higher MMR was noted in 2021, 2020 and 2019. } \\
\hline
\end{tabular}

\begin{tabular}{|ccc|}
\hline Age Group & No. of Deaths & Percentage \\
$20-25$ yrs. & 26 & $54 \%$ \\
$25-30$ yrs. & 12 & $25 \%$ \\
$<20$ yrs. & 2 & $4.1 \%$ \\
$>30$ yrs. & 8 & $16.6 \%$ \\
\hline \multicolumn{2}{|c|}{ Table 2. Age Wise Distribution of MMR } \\
\hline Age group between 20 to 25 years showed maximum deaths. \\
\hline
\end{tabular}


There were $40 \%$ vaginal births and 50\% LSCS and 4\% deaths due to ectopic pregnancy, $4 \%$ mothers undelivered and $2 \%$ deaths due to miscarriage in this study. $68.75 \%$ were uneducated and $31.25 \%$ had literacy just above $10^{\text {th }}$ class. A majority $95.8 \%$ belonged to low socioeconomic group and 4.1 $\%$ were from middle income group. Most cases were unbooked (91.69\%) and only $8.3 \%$ were booked cases, 3 or more AN visits. $37.5 \%$ of cases were less than 37 weeks of pregnancy and $29.1 \%$ belonged to term gestation at the time of death. Peripartum C-section was done in moribund cases to save foetus. There were $81.25 \%$ of referred cases and $18.75 \%$ in house cases.

\begin{tabular}{|c|c|c|}
\hline Parity Index & No. of Deaths & Percentage \\
\hline Primi & 15 & $31.25 \%$ \\
\hline G2 G3 & 27 & $56.25 \%$ \\
\hline G4 \& > & 6 & $12.5 \%$ \\
\hline \multicolumn{3}{|c|}{ Table 3. Parity Index and MMR } \\
\hline \multicolumn{3}{|c|}{$\begin{array}{l}\text { G2 G3, primi formed the majority of study population. Major cause of MMR due to } \\
\text { direct cause was } 77 \% \text {. Indirect cause accounted for } 23 \% \text {. }\end{array}$} \\
\hline Cause of Death & No. of Deaths & Percentage \\
\hline Direct cause & 37 & $77 \%$ \\
\hline Indirect cause & 11 & $23 \%$ \\
\hline \multicolumn{3}{|c|}{ Table 4. Cause of Death and MMR } \\
\hline
\end{tabular}

\begin{tabular}{|ccc|}
\hline Cause of Death & Number of Deaths & Percentage \\
PIH, preeclampsia and eclampsia (HDP) & 17 & $35 \%$ \\
Obstetric haemorrhage (APH \& PPH) & 12 & $25 \%$ \\
Sepsis & 3 & $6.25 \%$ \\
Pulmonary embolism/AF embolism & 5 & $10.4 \%$ \\
Ectopic pregnancy & 2 & $4 \%$ \\
\hline Table 5. Direct Causes of MMR \\
\hline
\end{tabular}

Direct cause was responsible for $77 \%$ of maternal deaths. Hypertensive disorders of pregnancy, $35 \%$, was the leading direct cause of death followed by obstetric haemorrhage in $25 \%$ and pulmonary embolism/AF embolism in $10.4 \%$ of cases.

\begin{tabular}{|ccc|}
\hline Cause of Death & Number of Deaths & Percentage \\
Anaemia ( moderate + gross) & 35 & $72.9 \%$ \\
Jaundice complications in pregnancy & 1 & $2.08 \%$ \\
Bronchopneumonia & 3 & $6.25 \%$ \\
Meningoencephalitis & 1 & $2.08 \%$ \\
Diabetic ketoacidosis & 2 & $4.16 \%$ \\
\hline Table 6. Indirect Causes of MMR \\
\hline \multicolumn{2}{|c}{} \\
\hline
\end{tabular}

Indirect causes were responsible for $23 \%$ of maternal deaths. Moderate $(<9 \mathrm{gm})$ and severe anaemia $(<7 \mathrm{gm})$ was responsible for death in majority of cases. Gross of $\mathrm{Hb}<7 \mathrm{gm}$ was observed in 18 cases accounting for $37.5 \%$ of cases. Anaemia (moderate + gross) accounted for majority, 72.9\%, of indirect causes of MMR followed by bronchopneumonia and diabetic ketoacidosis.

\section{DISCUSSION}

Many of direct causes of maternal deaths are potentially preventable and treatable. Maternal mortality is a key health indicator. Obstetric haemorrhage (especially after child birth), sepsis in pregnancy \& puerperium, preeclampsia \& eclampsia, unsafe abortions - all these contribute to a big chunk of maternal deaths.1,3,5

For the period of 2016-18, Maternal Mortality Ratio (MMR) of India is $113 / 100,000$ live births, as declared by national registration system data, declining by 17 points, from $130 / 100,000$ live births in 2014-16. According to this, 2,500 additional mothers saved yearly in 2018 as compared to 2016. Total estimated annual maternal deaths show a decline from from 33800 maternal deaths in 2016 to 26437 deaths in 2018. ${ }^{3}$

Present study included 48 maternal deaths, with MMR of 142.35 per one lakh live births. This is higher than national average of $113 / 100,000$ live births. ${ }^{3}$ Andhra Pradesh with a birth-rate of $21.3 \%$ has MMR of 154 (2003). Women in reproductive age suffer from disability \& death, mainly due to complications during pregnancy and child birth. Poverty, unhygienic living, illiteracy, infections \& unregulated fertility together synergise and result in health problems of mother \& new-born. At the same time, average infrastructure and less effective public health services are also responsible for the existing poor obstetric care. ${ }^{6}$

In the present study, higher MMR was noted in 2021(202.07\%), 2020(165.75\%) This may be due to more high-risk referrals in Covid pandemic period and less availability of peripheral healthcare facility. Referred cases accounted for majority $81.25 \%$ cases, in-hospital cases being only $18.75 \%$. $68.75 \%$ were uneducated and $31.25 \%$ had literacy up to 10 th class. A majority of $95.8 \%$ belonged to low socioeconomic group and $4.1 \%$ were from middle class. Most cases were unbooked contributing to $91.69 \%$ and only $8.3 \%$ were booked cases ( 3 or more AN visits). Unbooked cases in poor health state coming from rural and peripheral areas contributed to higher maternal mortality ratio in present study. Ours being a tertiary care centre located in rural area, receiving complicated referral cases in moribund state. 81.25\% of cases were referred from (CHCS, PHC \& private hospitals) towns and villages around Anantapur.

Majority of deaths occurred in age group between 20 to 25 years in our study. G2 G3 formed a larger segment of 27 cases $(56.25 \%)$, followed by primipara 15 cases $(31.25 \%)$. Literature comparison shows maximum maternal deaths in the age group between 20 to 24 years, in multiparous women, women from rural areas, unbooked patients, low socioeconomic status and in illiterate women.7,8,9

Direct causes were responsible for $77 \%$ of maternal deaths and indirect causes for 23\%. Hypertensive disorders of pregnancy (PIH, Preeclampsia and eclampsia) were leading direct causes of death followed by obstetric haemorrhage (APH, PPH, 3rd stage bleeding). Obstetric haemorrhage accounts for $25 \%$ of cases in our study and can be well tackled by universally adopting to active management of third stage of labour by giving IM oxytocin. With wide availability and usage of misoprostol tablets and carboprost injections there is reduction in maternal deaths due to postpartum haemorrhage in recent times. Direct causes related to maternal deaths accounted for $72.5 \%$ in a study by Bhaskar et al. Haemorrhage (26.66\%), eclampsia (26.66\%), and sepsis (18.33\%) was the major direct causes of maternal deaths, whereas only one maternal death $(0.83 \%)$ was due to obstructed labor. ${ }^{5}$ Singla et al. reported similar higher incidence of HDPs followed by obstetric haemorrhage and sepsis. ${ }^{10}$

Indirect causes contributed to $23 \%$ of maternal deaths. Moderate $(<9 \mathrm{gm})$ and severe anaemia $(<7 \mathrm{gm})$ were responsible for death in majority of cases. Anaemic mothers tolerated haemorrhage poorly and succumbed to death. Gross $\mathrm{Hb}<7 \mathrm{gm}$ was observed in 18 cases accounting for $37.5 \%$ of 
cases. Several studies from India reported that indirect causes were responsible for $18 \%$ to $34 \%$ of cases. Anaemia, jaundice, sepsis and cardiac disease were responsible for

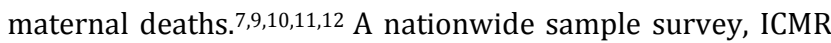
2003, observed that $23.4 \%$ deaths occurred during antepartum period, $21 \%$ deaths were due to indirect causes, and $59.1 \%$ deaths occurred in health facilities. ${ }^{6}$ The majority of deaths occur due to direct causes such as bleeding, hypertensive disorders and infections was noted by Ronsman et al. 5

Large number of maternal deaths is due to eclampsia, haemorrhage and anaemia. Appropriate treatment at periphery and referral to higher centre in time may prevent majority of maternal deaths. ${ }^{6}$ 'Third delay' is raising a concern which may occur if a pregnant woman reaches a health care facility seeking institutional delivery after enquiring at two or more hospitals. This may lead to an increase in proportion of maternal deaths in hospitals. Critical observation says $23(28.8 \%)$ women had to attempt to obtain care at two or more hospitals. ${ }^{13}$ Communication between health workers \& first referral centre and higher referral centres in an effective way is much needed. These factors along with strengthening quality care to manage complications during pregnancy - could be an important element in preventing deaths resulting from third delay in hospitals. Complications related to pregnancy and child birth are potentially preventable with high quality care obstetric practice. Proper antenatal care to prevent and treat anaemia, early detection of high-risk factors, prediction of preeclampsia and instituting low dose aspirin early in pregnancy may all contribute to lower maternal mortality. Emphasis on institutional deliveries and ease of transport of pregnant women from rural areas to community hospitals and tertiary care centres has significantly played a key role in decreasing maternal mortality.

\section{CONCLUSIONS}

Maternal deaths are common in poor, unbooked, uneducated patients hailing from rural area. Hypertensive disorders of pregnancy, obstetric haemorrhage are major direct causes of maternal deaths, anaemia being the commonest indirect cause. Quality antenatal care in pregnancy and skilled timely care during childbirth are need of the hour to achieve the goals set to decrease maternal mortality ratio.

Data sharing statement provided by the authors is available with the full text of this article at jemds.com.

Financial or other competing interests: None.

Disclosure forms provided by the authors are available with the full text of this article at jemds.com.

\section{REFERENCES}

[1] Trends in maternal mortality: 2000 to 2017: estimates by WHO, UNICEF, UNFPA, World Bank Group and the United Nations Population Division. Geneva: World Health Organization 2019.

[2] World Health Organization. Trends in maternal mortality: 1990 to 2013. Estimates by WHO, UNICEF, UNFPA, the World Bank and the United Nations Population Division. Maternal health|UNICEF India 2014.

[3] Wilson A. Interventions to reduce maternal mortality in developing countries: a systematic synthesis of a evidence. University of Birmingham research archive. The University of Birmingham August 2013.

[4] Estimates of maternal mortality ratios in india and its states a pilot study sponsored by department of family welfare ministry of health and family welfare Govt. of India, Institute for Research in Medical Statistics Indian Council of Medical Research July 2003.

[5] Murthy BK, Murthy MB, Prabhu PM. Maternal mortality in a tertiary care hospital: a 10-year review. Int J Prev Med 2013;4(1):105-9.

[6] Ronsman C, Graham WJ. Maternal mortality: who, when, where, and why. Lancet 2006;368(9542):1189-200.

[7] Agrawal N, Uppadhaya SK, Hakim A, et al. An analysis of trends in maternal mortality at a tertiary care teaching hospital of Western Rajasthan, India: a four year retrospective study. Int J Community Med Public Health 2017;4(3):864-7.

[8] Lilare RR, Narlawar UW, Lillore R. Maternal mortality in a tertiary care hospital of central India: a 5 years review. JMSCR 2017;5(12):31820-4.

[9] Singla A, Rajaram S, Mehta S, et al. A ten year audit of maternal mortality: millennium development still a distant goal. Indian J Community Med 2017;42(2):102-6.

[10] Bhattacharyya SK, Majhi AK, Seal SL, et al. Maternal mortality in India: a 20-year study from a large referral medical college hospital, West Bengal. J Obstet Gynaecol Res 2008;34(4):499-503.

[11] Jain A, Gupta SC, Misra SK, et al. Trend and causes of maternal mortality among women delivering in S. N. Medical College Hospital, Agra. Indian J Public Health 2009;53(1):47-8.

[12] Ramanathan M. Addressing the 'third delay' in maternal mortality: need for reform. Indian J Med Ethics 2009;6(4):211-2.

[13] Shah P, Shah S, Kutty RV, et al. Changing epidemiology of maternal mortality in rural India: time to reset strategies for MDG-5. Trop Med Int Health 2014;19(5):568-75. 